Article

\title{
Rural Tourism Accommodation Prices by Land Use-Based Hedonic Approach: First Results from the Case Study of the Self-Catering Cottages in Asturias
}

\author{
Celia Bilbao-Terol ${ }^{1, *}$, Verónica Cañal-Fernández ${ }^{1}$, Luis Valdés ${ }^{2}$ and Eduardo Del Valle ${ }^{2}$ \\ 1 Department of Economics, University of Oviedo, 33006 Oviedo, Spain; vcanal@uniovi.es \\ 2 Department of Applied Economics, University of Oviedo, 33006 Oviedo, Spain; lvaldes@uniovi.es (L.V.); \\ valleeduardo@uniovi.es (E.D.V.) \\ * Correspondence: cbilbao@uniovi.es; Tel.: +34-985103722
}

Received: 2 August 2017; Accepted: 19 September 2017; Published: 22 September 2017

\begin{abstract}
This study analyses the impacts of environmental amenities associated with agricultural and silvicultural land use on the price of rural tourism accommodation in Asturias (Spain). A hedonic price model that relates the price of rural accommodation to environmental amenities as well as equipment, services offered, and the locational characteristics of the accommodation is estimated. The rural accommodations in the study are the self-catering cottages, the intrinsic features of which promote the development of rural tourism sustainability. Geographic information systems (GIS) data are used to measure the location and the proximity to amenities of these self-catering cottages. The main results indicate that agricultural land use has an important impact on the price of accommodation in self-catering cottages. Specifically, a high percentage of grassland in the municipality where the self-catering cottage is sited has a positive effect on rental prices, while a high percentage of arable crops has the opposite effect. The analysis is interesting for decision-making in the context of environmental policies, land use conflict resolution, and rural tourism sustainability.
\end{abstract}

Keywords: environmental amenities; geographic information system; hedonic price model; rural heritage; rural land use; rural tourism sustainability; self-catering cottages

\section{Introduction}

Agricultural, livestock, and forestry land uses affect their environmental surroundings, producing simultaneous positive externalities, including the protection of natural resources, open spaces, and wildlife habitats, and negative externalities such as pollution from fertilizers and pesticide [1], the degradation of the landscape due to buildings housing livestock, and air/water pollution resulting from manure surpluses [2]. The valuation of these externalities is essential for designing more effective environmental policies, but there is no market for them. Several methods exist in the economic literature to correct this deficiency such as contingent valuation, hedonic method, travel cost, damage avoidance cost, and multi-criteria techniques. This study deals with the hedonic price method [3] applied to rural environmental issues.

Applications of hedonic methods to the environmental field are based on the observation that some heterogeneous goods or services are valued by a number of economic and environmental characteristics; thus the decomposition of the price of the good or service can reveal information on the value of those characteristics [4]. In this paper, the heterogeneous service is rural tourism accommodation. The hedonic method takes into account the relationship between the price of rural accommodation and its environmental quality, and this makes it possible to obtain the implicit price of the environmental amenities. 
The study is carried out at a regional level because, in Spain, many policies bearing executive and legislative power have been transferred to the regions. Hence, this provides a framework reflecting substantial differences in the actual regional configuration of rural environments and tourism.

Our study explores the impacts of environmental amenities associated with agricultural and silvicultural land use on the price of self-catering cottages for the municipalities in the Autonomous Community of Asturias in the North of Spain. The self-catering cottages are autonomous and independent rural buildings that reflect the traditional architecture of the area and are rented for exclusive use by tourists.

Geographical Information Systems (GIS) data are used to measure the location and the proximity to amenities of rural tourism accommodation. The use of Geographical Information Systems (GIS) and the availability of geo-referenced information on environmental quality have increased the flexibility with which environmental amenities can be linked to house locations, allowing for the improved accuracy of proximity to natural characteristics in hedonic method studies [5].

Applications of the hedonic method to analyse the interrelationships between the price of rural tourism and agriculture land use are scarce [6-9], and none of the models in the above studies are specified with GIS measures. However, GIS is useful for obtaining local environmental information and including local environment variables in the hedonic models, addressing the problem of omitted environmental variables bias [10]. Therefore, a contribution of this article to the literature in this field is the application of the hedonic method with GIS measures.

The results could prove valuable for decision-making with respect to environmental policies. They can be used to design environmental subsidies and taxes and may serve as a starting point for applied cost-benefit analysis to assess environmental improvement. Moreover, the results are interesting for accommodation managers and owners who seek to optimize their investment, for the tourist administration when designing tourism policies, and, finally, for tourists by facilitating information to help them choose their accommodation.

The paper is structured as follows: Section 2 presents a brief review of the literature on the subject. Section 3, Materials and Methods, describes the study area, that is, Asturian geography and the region's environmental surroundings, and explains the methodology used, providing a descriptive analysis of the data and variables included in the empirical analysis. Section 4 presents the empirical analysis and the discussion of the results. Finally, Section 5 presents the most important conclusions that can be drawn from the study.

\section{Literature Review}

The use of traditional rural buildings for tourism is considered sustainable when the main reference is made to the preservation of the cultural heritage they represent and the conservation of the countryside where they are located. This was one of the main objectives of European Policy on rural tourism [11-13].

Several works consider this issue, highlighting heritage as a catalyst for rural regeneration. In this regard, the studies of Prideaux [14], Porto et al. [15], De Montis et al. [16], and Leanza et al. [17] should be noted as they analyze the viability of recuperating rural buildings for use in tourism. Prideaux [14] analyses the viability of a rural heritage tourism development programme in the Australian Queensland Heritage Trails Network. To achieve this object, he compares the project selection criteria adopted by the Queensland Heritage Trails Network with the community consultative process used to establish the feasibility of a Rural Heritage Interpretation Centre proposed for Gatton Shire in southeast Queensland. Porto et al. [15] and Leanza et al. [17] design a planning strategy for a tourist itinerary located in rural areas of southeastern Sicily. The Donnafugata Castle is chosen as a specific heritage site, and it connects several heritage attractions located in the rural area surrounding the castle. De Montis et al. [16] analyse the viability of installing a scatted hotel accomodation (albergo diffuso) in an old abandoned rural Italian village. 
Others studies $[18,19]$ deal with the need to conserve and protect rural architectural heritage. Garcia and Ayuga [18] propose a method for the study of building reuse, and some of the common mistakes made in this type of work are discussed for Spain. Porto and Gascone [19] carry out a study aimed at the characterization of the building materials and techniques used for the construction of a number of building components that make up the external envelope of traditional rural buildings. The application of the method to a homogeneous area of the Etna Regional Park (Italy) highlighted the need to improve the technical norms of the park's Territorial Coordination Plan to respect the building characteristics of the traditional rural buildings located in the protected area.

In their study on Tuscany concerning different mechanisms that either enable or hinder the transition of rural economies towards tourism, Randelli et al. [20] consider the contribution of tourism in the recovery of farmhouses but, at the same time, warn against the urbanization of rural areas with new buildings.

LePan and Barbieri [21] study agro-tourism in the USA and consider that all policies related to an increase of on-farm revenues gain importance because they foster the rural economy and protect rural heritage, with farmers increasing their efforts to obtain benefits from their own heritage assets. As Cànoves et al. [22] concluded, rural tourism also provides economic benefits and preserves house and family heritage.

Therefore, rural tourism and agro-tourism seem to be suitable tools to preserve rural tangible heritage, but the relationship between tourism and agriculture is very delicate as there has been a general and gradual abandonment of farming in favour of tourism $[8,23]$. In addition, the most valued accommodations are those that are situated in pleasant and quiet surroundings that do not take into account or avoid agricultural activities [8,24].

The application of the hedonic method to evaluate environmental amenities for the rural tourism market began in 2000 and can be classified into two main types. A first group of studies analyze how environmental surroundings influence rural tourism. Taylor and Smith [25] studied the market power of site-specific environmental amenities, in particular the access to coastal beaches, using the data for rental prices of beach properties in North Carolina. Hunt et al. use [26] a spatial hedonic analysis to examine the impact of forest harvesting and other angling site attributes on prices for trips to Ontario's fly-in fishing sites. A GIS was used to collect information related to land cover data. Hamilton [27] analyses the effect that the proximity of coastal and other landscape features has on rural tourism demand in the coastal district of Schleswig-Holstein (Germany). Mollard et al. [28] study the role of environmental and regional characteristics used by tourism operators as a means of differentiating services. Anderson and Hoffmann [29] include spatial econometrics techniques in their hedonic estimation in order to examine local and special competition for farm tourism services. Suarez Vega et al. [30] also use spatial econometrics techniques to check the spatial autocorrelation of rental prices of rural houses in Gran Canaria (Spain). Nelson [31] estimates hedonic price models for vacation rental houses located near a lake and a ski-golf resort in rural western Maryland (USA).

A second group discusses the interrelationships between rural tourism and agriculture. In this vein, Le Goffe [7] applies the hedonic method to evaluate some of the external effects of agricultural activities by examining the price of rural accommodation in Britanny (France). Fleischer and Tchetchick [8], using a hedonic pricing technique, investigate whether the price of rural tourism accommodation on working farms differs from accommodation without agricultural activity. Vanslembrouck et al. [9] examine the impact of agricultural activities on the prices of rural tourism in Flandes (Belgium). In the same way, Bilbao-Terol and Valdés [6] analyse how the characteristics of the environment associated with agricultural activities influence the prices of rural accommodation in Asturias (Spain). Le Goffe [7], Vanslembrouck et al. [9], and Bilbao-Terol and Valdés [6] obtain that rural tourism market values positively the presence of permanent grassland and negatively the presence of fodder crops and livestock in the area surrounding the accommodation. In regard to the presence of forest, Le Goffe [7] and Vanslembrouck et al. [9] obtain a negative but statistically 
insignificant effect on the price of rural accommodation, while Bilbao-Terol and Valdés [6] obtain a positive and significant effect. Our paper is a contribution to this last group of studies.

\section{Materials and Methods}

\subsection{Study Area}

Asturias is one of the 17 Spanish Autonomous Communities and is situated on the northern coast of Spain. Its extension covers an area of $10,603.57 \mathrm{~km}^{2}$ [32]. Asturias is bordered by the province of Cantabria to the east, by Castilla y León and the mountain range known as the Cordillera Cantábrica to the south, by Galicia to the west, and by the Cantabrian Sea to the north (Figure 1).

Its climate is Atlantic with mild temperatures, and it often rains throughout the year; the area is known for its green landscapes. The Asturian coastline boasts golden sandy beaches with steep cliffs and inland areas with abundant green valleys, fast flowing rivers, meadows, and lots of pastures for livestock, including goat, sheep, and cattle farming. In addition, vast wooded areas and forests of oak, beech, walnut, chestnut trees, and eucalyptus, on the coast, cover the region. The landscape spans from the coast to smaller mountain ranges finishing in the high mountainous areas of the Picos de Europa in the Cordillera Cantábrica, which are over $2000 \mathrm{~m}$ high.

\section{ASTURIAS IN FIGURES}

Population: 1,058,976 inhabitants.

Area: $10,603.57 \mathrm{sq} \mathrm{km}, 30 \%$ of which comprises protected areas.

Borders on: The Bay of Biscay (Cantabrian Sea) to the north, while to south the Cantabrian Mountains separate the Principality from Castile and León. The estuaries of the Rivers E0 and Deva respectivelymark the boundary with the neighbouring regions of Galicia and Cantabria.

Capital: Oviedo

Major cities: Avilés, Gijón and Oviedo.

Administrative division: Boroughs. Asturias has 78 boroughs or municipalities.

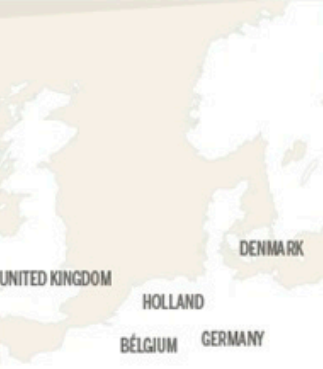
FRANCE

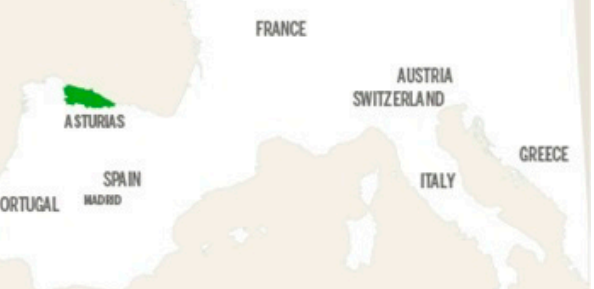

Âvilts GiJón

OVIEDO

Figure 1. Asturias in figures. Source: Tourism Asturias [30].

According to the data provided by the Asturian Society of Economic and Industrial Studies (SADEI) [33], the main use of the Asturian countryside in 2014 was forestry (58\%), which has been on a continual increase (in 2010 the figure was $44 \%$ ), followed by pastureland (30\%). Farmland only represents $2 \%$ of the regional area (Figure 2).

Apart from grasslands, the agriculture in Asturias is based on fodder crops for the ranching industry (livestock) and the cultivation of fruit trees (important to the regional industry of cider) or other crops such as kiwis or berries [33] (Table 1). 


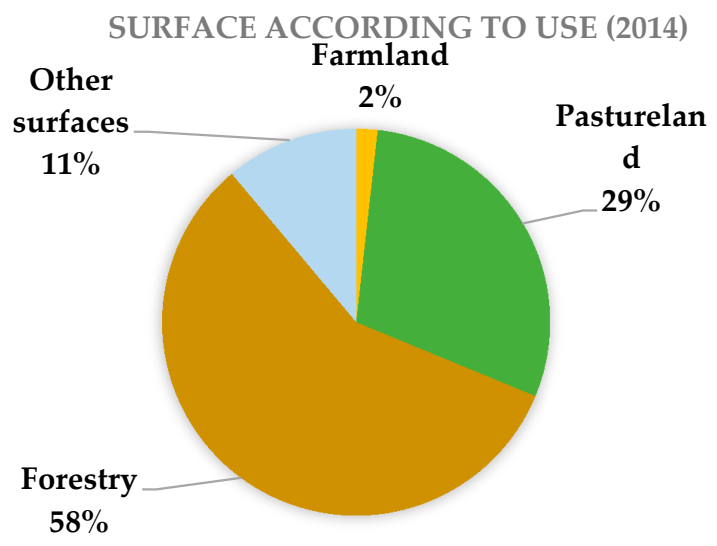

Figure 2. The surface of Asturias according to use (2014). Source: Asturian Society of Economic and Industrial Studies (SADEI )from data of the Ministry of Agriculture and Autonomous Resources [33]. (Forestry: timber land and woody mountain areas. Open land. Other surfaces: rough grazing, unproductive terrain, non-agricultural land, rivers, and lakes).

Table 1. Agricultural surface according to crop types (2014).

\begin{tabular}{|c|c|c|c|c|}
\hline & \multicolumn{2}{|c|}{ Cultivation } & \multicolumn{2}{|c|}{ Production } \\
\hline & $\left(\mathrm{Km}^{2}\right)$ & $(\%)$ & (Tons) & $(\%)$ \\
\hline Vegetables & 6.91 & $0.20 \%$ & 10,842 & $0.88 \%$ \\
\hline Tubers & 10.10 & $0.30 \%$ & 22,220 & $1.80 \%$ \\
\hline Legumes & 9.00 & $0.26 \%$ & 650 & $0.05 \%$ \\
\hline Cereals & 4.55 & $0.13 \%$ & 910 & $0.07 \%$ \\
\hline Fodder crops & 201.74 & $5.91 \%$ & 816,728 & $66.19 \%$ \\
\hline Fruit & 46.81 & $1.37 \%$ & 16,241 & $1.32 \%$ \\
\hline Flower and plant cultivation & 0.20 & $0.01 \%$ & 980 & $0.08 \%$ \\
\hline Grassland & 3133.87 & $91.82 \%$ & 365,384 & $29.61 \%$ \\
\hline
\end{tabular}

Source: SADEI and Government of Asturias (Agricultural division) last date: 25/09/2016 [33].

Nature and the countryside are very important aspects of the global governance of Asturias, which seeks for protected areas to contribute to sustainability (environmental and biodiversity), which will provide social and economic benefits by supporting local livelihoods. As an indicator, the Sites of Community Interest (SCI) represent nearly 30\% of the total area of Asturias, and the protected area includes one national park, five nature parks, 10 nature reserves, and 10 protected natural areas, as well as 40 natural monuments [33-35]. Some zones are protected by different figures at the same time (see Table 2 and Figure 3).

Table 2. Protected area.

\begin{tabular}{cccc}
\hline Natura 2000 Network & Num & Protected Area $\left.\mathbf{( K m}^{\mathbf{2}}\right)$ & \% over Asturias \\
\hline Sites of Community Interest (SCI) & 49 & 3090.46 & 29.15 \\
Special Protection Areas (SPAs) & 13 & 2391.72 & 22.56 \\
\hline Protected Figures & Num & Protected Area $\left(\mathbf{K m}^{\mathbf{2}}\right)$ & \% over Asturias \\
\hline National Park & 1 & 275.54 & 2.60 \\
Nature Parks & 5 & 1676.92 & 15.82 \\
Nature Reserves & 10 & 127.02 & 1.20 \\
Protected Landscapes & 10 & 1373.28 & 12.95 \\
Protected Natural Areas & 40 & 43.58 & 0.41 \\
Biosphere reserves & 6 & 2337.78 & 22.05 \\
\hline
\end{tabular}

Source: SADEI obtained from Sistema de Información Ambiental del Principado de Asturias SIAPA 2015 [33]. 

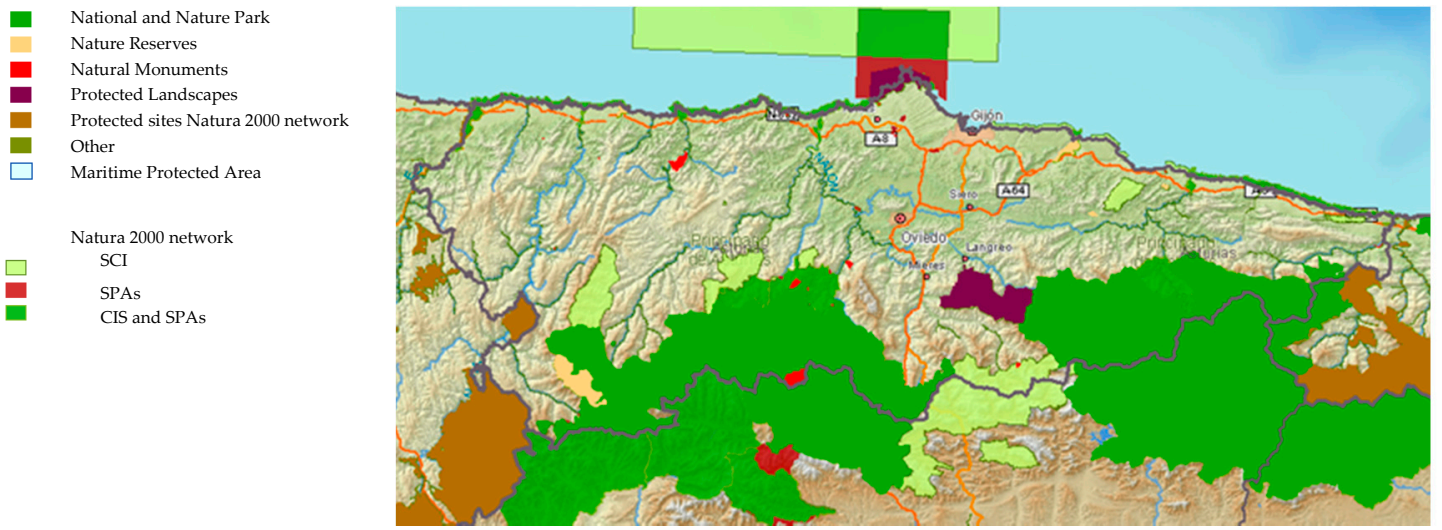

Figure 3. Protected Areas in Asturias in 2000; red indicates 'nature'. Source: Geographic information system from the Nature Data Bank (BDN). Ministry of Agriculture, Fisheries, Food, and Environment of the Government of Spain [35].

Industry is important in Asturias, especially in the central area, in which over $50 \%$ of the total population of 1,034,681 was concentrated in 2017 [36]. Nevertheless, the services sector has increased significantly in importance in recent decades, and its contribution to the economy now represents over $70 \%$ of the gross value added GVA (see Figure 4). According to statistics from the Tourist Information System of Asturias [37], tourism activities represent 10.3\% of GVA, with 2,204,941 tourists lodged in collective tourism accommodation; this increasing by $5.03 \%$ in 2016 . Overnight stays increased by $7.68 \%$, with a total of $5,306,249$ [38].

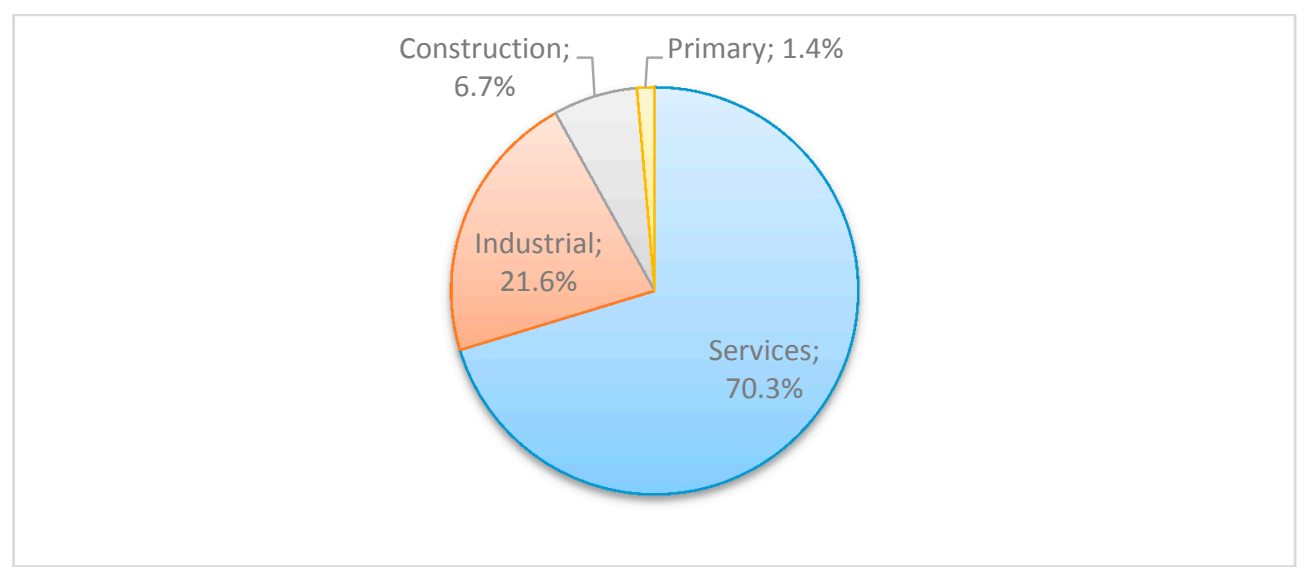

Figure 4. Gross value added GVA distribution by sector in 2016, shown in percentages Source: National Statistics Institute INE. Spanish Regional Accounts, First Estimation for 2016 [36].

The Asturian government/ DMO's (destination management organization) tourism politics logo or slogan, 'Natural Paradise' [32], and regional tourism statistics supported by Tourist Information System of Asturias [37] reflect that the main strengths of the region's tourism are nature, the proximity between the mountains and the coast, the diversity of activities, the gastronomy (cider, beans, cheese ... ), and the culture, with monuments that have been declared World Heritage sites by UNESCO (pre-Romanesque art, unique in the world), archaeological sites, caves, museums, and the primitive pilgrim route of St James, etc., as well as the great offer of rural accommodation. Asturias also pioneered the development of rural tourism, opening the first rural hotel in Spain, 'The Rectory', in Taramundi, a small municipality in the interior of the region. 
The development of rural tourism in Spain has been characterized by two remarkable characteristics [6,22,39-43]. The first one, as occurred in other European regions [20,43-45], was the presence of the subsidies received from European Funds and Community initiatives such as LEADER (Liaison Entre Actions de Développement de l'Économie Rurale) or national programmes like PRODER (Rural Development Project), the goals of which were the socio-economic diversification of rural economies to stop the depopulation of rural areas and preserve the rural environment and rural heritage.

The second was the transfer of tourism competences to the Autonomous Communities (Spanish regional divisions made up of one or more provinces). The competences for legislation, management, and promotion have been transferred from central to regional government, the latter having full powers to create regional laws, rules, and regulations. Since 1981, Autonomous Communities have started a process to regulate tourism activity and rural tourism. This has resulted in considerable disparity as far as rural tourism legislation is concerned, with large differences, due to regional laws leading to different typologies and different types of rural accommodation (like names, services included, size, location conditions) [40,41].

With the transfer of competences, Asturias has its own rules and laws for its tourist sector. Currently, there are four modalities of rural accommodation in Asturias: rural hotels, rural apartments, and country houses, which can be bed-and-breakfast cottages or alternatively rented self-catering cottages. The speciality of agrotourism can be applied to all rural tourism accommodation as long as customers are offered farming activities. The maximum capacity of the country houses is 15 places, with a maximum of seven rooms, and they are classified by a three level category system (one, the minimum, two, or three, the maximum) using the triskele (Celtic symbol) to represent the quality of their facilities and services.

Self-catering cottages are autonomous and independent rural buildings that respond to the traditional architecture of the area and are rented for the exclusive use of tourists. Overall, they are ancient farms or rural dwellings that are re-used for tourism accommodation and are located nearby or in the centre of a rural village. This kind of accommodation has several advantages from the point of view of sustainability [16]. Firstly, it does not require further land to be used for the purpose of constructing new residential buildings. This minimises the environmental impact on rural areas. Secondly, it prevents the depopulation of small rural towns and promotes the recuperation of abandoned rural dwellings. Thirdly, it respects the cultural environment and the authenticity of the accommodation offered [46]. Fourthly, it offers visitors the opportunity of 'living in the area' by taking part in the social life of the village. Finally, it preserves the cultural heritage and the conservation of the countryside where they are located $[20,21]$.

At the beginning of 2017, in Asturias, there were 1,141 country houses, 234 bed and breakfasts, and 907 self-catering cottages [37]. The growth of self-catering cottages [47] can be explained by the higher interest and benefits to tourist segments such as families with children or groups of friends $[47,48]$. On the other hand, the type of businesses that rely on small dwellings rented with a maximum capacity of 15 places and are run by entrepreneurs whose main job is not tourism and who have a lack of tourism management skills [49] may prefer renting the lodge as a whole because it is easier to manage and has fewer costs than an accommodation facility that rents single rooms, which need a diary customer service [50]. Our study is reduced to self-catering cottages because they are the most numerous, and it is of interest to have a higher sample in order to carry out the hedonic estimation. Additionally, this type of lodging is also a link to sustainable heritage.

The Tourist Information System of Asturias [37,47] analyses the tourism demand in Asturias through a personal survey at tourists' destinations. The characteristics of rural tourism demand in Asturias show that the Spanish market represents over the $88 \%$ of the total rural demand (Madrid, Castilla y León, and País Vasco are the main Autonomous Communities) as long as international demand signifies $7.5 \%$ and domestic tourism (Asturian) only $4.5 \%$. The average length of stay of rural tourists is four to five nights, and they principally used the Internet ( $88 \%$ ) to look for information about 
rural accommodation. The services were booked directly with the rural accommodation (no package trips are used) and were mainly booked via the Internet (34\%) or over the telephone (29\%). The main purpose of trips to rural accommodation in Asturias is holidays and leisure, and the main means of transport used by rural tourists are private motor vehicles $(96 \%)$. The situation, environment, and price (quality-price ratio) determine the main reasons why tourists to book certain rural accommodation. The levels of satisfaction with the visit and lodging are quite high (with a mean of 8 out of 10).

\subsection{Methodology}

The hedonic price method regards goods or services as a set of characteristics, and their price is a function of these. The value of each characteristic is its implicit or hedonic price because it cannot be observed in the real market. However, if a good or service contains enough models with different combinations of characteristics in the market, the hedonic price can be estimated. The mapping that determines the market price of a good or service through these characteristics is called the hedonic price function.

In this section, Rosen's method [3] is applied to the rural tourism market. It assumes that the service of accommodation offered by a rural establishment, $i$, is composed of a vector of intrinsic or particular characteristics, $\mathbf{c}_{i}$, such as category, capacity, or equipment and a vector of environmental surroundings, $\mathbf{e}_{i}$, such as agricultural land use, views, landscape elements, wildlife habitats. Another vector is the location or geographical characteristics, $\mathbf{l}_{i}$, which includes the distance to certain services, places of interest, environmental resources, and amenities. Assuming that the rural tourism market is in equilibrium and is perfectly competitive, the hedonic price function for rural accommodation, $P_{i}$, is:

$$
P_{i}=\mathrm{f}\left(\mathbf{c}_{i}, \mathbf{e}_{i}, \mathbf{l}_{i} ; \boldsymbol{\beta}, \boldsymbol{\gamma}, \boldsymbol{\delta}\right)+u_{i}
$$

where $\beta$ stands for the vector of the coefficients that are estimated for the intrinsic characteristics of accommodation, $\gamma$ stands for the vector of the coefficients that are estimated for the environmental surroundings, and $\delta$ is analogous for the location characteristics. The random error is represented by $u_{i}$. The hedonic price function is an overview of the various situations of equilibrium for different valuations of tourism and for different levels of profits of the suppliers.

After Function (1) has been estimated, it allows the prediction of the price of any rural accommodation with characteristics $\mathbf{c}_{i}$, $\mathbf{e}_{i}$, and $\mathbf{l}_{i}$ :

$$
\hat{P}_{i}=\mathrm{f}\left(\mathbf{c}_{i}, \mathbf{e}_{\mathbf{i}}, \mathbf{l}_{i} ; \hat{\boldsymbol{\beta}}, \hat{\gamma}, \hat{\mathbf{\delta}}\right)
$$

In addition, Function (2) allows us to calculate the implicit or hedonic prices for each characteristic. The hedonic price of a characteristic is equal to both the average marginal willingness of tourists to pay for an additional unit of the characteristic embedded in the tourism product and also concerns the amount of money that firms are willing to receive in order to embed the characteristics in the final product [51]. As a result, the implicit price of individual characteristics can be deduced. For instance, the hedonic price for an intrinsic characteristic measured in discrete quantities, $k\left(p_{k}\right)$ of any tourism accommodation $i$ can be computed as follows, where $\mathbf{c}_{\{-k\}}$ is the vector of all intrinsic characteristics but the $k$ th [52]:

$$
\hat{p}_{k}=\mathrm{f}\left(c_{k}+1, c_{\{-k\}} ; \hat{\boldsymbol{\beta}}\right)-\mathrm{f}\left(c_{k}, c_{\{-k\}} ; \hat{\boldsymbol{\beta}}\right)
$$

while, for continuous characteristics, the hedonic price for a particular (intrinsic) characteristic is:

$$
\hat{p}_{k}=\partial \mathrm{f}\left(\mathbf{c}_{i}, \hat{\boldsymbol{\beta}}\right) / \partial c_{k}
$$

The hedonic prices are defined as the price of each characteristic in each one of the $k$ implicit markets, ceteris paribus [53].

The hedonic price method consists of a second stage in which, using the hedonic prices already calculated (Functions (3) and (4)) in the first stage, the supply and demand equations are estimated for 
each characteristic. In this paper, only the function of hedonic prices is estimated. This is first stage, as the objective is to discover the implicit price of environmental amenities and it is not necessary to estimate any supply and demand equation.

\subsection{Data and Variables}

This section provides a descriptive analysis of the data and variables included in the specification of the model. The analysis is carried out with regional data from rural tourist accommodation in Asturias (North Spain). As noted above, there are four types of rural accommodation: rural hotels, rural apartments, bed-and-breakfast cottages, and self-catering cottages. It is unlikely that these types of rural accommodation offer the same kind of service [6]. According to the hedonic method, homogeneity in the service is necessary [27]. Therefore, the study is reduced to self-catering cottages.

In order to carry out the hedonic estimation, the prices of rural accommodation and their characteristics, that is, intrinsic, environmental, and localization, are needed. The intrinsic characteristics of self-catering cottages, their addresses, and prices were collected from The Official Asturias Tourism Accommodation brochure and accommodation register [32]; the most recent data available are for the reference year 2016. Following a filtering of the registers and database, we obtained 697 self-catering cottages ( $77 \%$ of the total self-catering cottages) with complete and valid information to analyse.

The choice of environmental characteristics raises difficult questions because of the lack of ecological indicators to measure externalities [54]. In this study, a global approach is adopted by measuring the use of land for agriculture and forestry in the municipality in which the cottages are located $[7,9,28,29]$. Also, information about the density of livestock in the municipality is provided. Data of the land use and the density of livestock in the municipality where the cottage is located has been collected from the Statistical Yearbook of Asturias; the most recent data available are for the reference year 2014 [33]. Unfortunately, no land use layer is available for Asturias; thus GIS could not be applied to measure the land use in the areas surrounding of the cottages.

In order to measure the location or geographical characteristics, GIS is used. We merge information about the locations and the characteristics of cottages and their distances to points of interest such as beaches, main cities, etc., obtained from three independent sources; The Official Asturias Tourism Accommodation Guide [32], the Statistical Yearbook of Asturias [33], and the CartoCiudad project [55], which provides the cartographic database. The data obtained from the first two sources allowed us to build the thematic database. CartoCiudad is an official cartographic database with national coverage of the thoroughfares network, defined from the cadastral urban background of all Spanish cities and villages, which also contains the census and postal districts. This project has been created from the harmonization and integration of official data provided by several of the main suppliers of Geographical Information in Spain such as the General Directorate of Cadastre, the Statistical Office, the Post Office, and the General Directorate of the National Geographic Institute. Due to the fact that Spain consists of more than 8000 municipalities, the production planning of CartoCiudad was structured in four years (2006 to 2009) so that it started with the production of the main and biggest municipalities of Spain ( $>50,000$ inhabitants), and currently it is involved in the generation of the smallest villages. The main reason for using CartoCiudad is that it provided the most accurate and disaggregated geographic information for Asturias at the time of our research.

A unique database was built with the aforementioned data using GIS. It is the ability of this system to reconcile spatial data from different sources, which allows the creation of new data sets. To do this, the geographic reference (ID (The linkage between symbol and meaning is established by giving every geographic feature at least one unique means of identification, a name or number usually just called its ID.)) that allowed us to geo-reference the thematic database was identified. The registered field in the three databases that enabled us to merge them is made up of the post codes published by the National Statistics Institute (INE) of Spain. 
Once the data collection has been carried out, the variables used in the hedonic estimation are defined. The dependent variable in the hedonic estimation is the rental price of cottages per night in high season as listed in the brochure (PRICE). Of course, the price listed may not match the actual price. To obtain the actual price, this listed price must be adjusted according to the accommodation's filling rate [56]. Since the variable used in the model is the rental price per night in high season, in this period the filling rate is $100 \%$, with the demand sometimes being even higher so that the contracted price will not match the brochure price.

The choice of the explanatory variables is based on a thorough review of the literature on applications of the hedonic method for the valuation of environmental amenities of rural tourism $[6-9,27-31]$. They are classified into three types:

- $\quad$ particular or intrinsic variables that are produced by the suppliers themselves

- land use in the areas surrounding the accommodation

- location variables

The particular or intrinsic variables are as follows:

- Category: as noted above, rural accommodation is classified into three different comfort categories. Two dummy variables have been created, a medium category (MCATEROGY) and a high category (HCATEGORY), which take a value of 1 if the self-catering cottage is in the medium or the high category and 0 otherwise. The reference category constitutes the low category. This kind of variable is included in almost all studies that apply the hedonic method to the tourism market $[6-9,28,29,51,57,58]$

- Accommodation capacity (PLACES): the total number of people who could be accommodated at the same time in the cottage. In addition, this variable is included in almost all studies of this kind $[6,7,9,28-30]$

- Wi-Fi available (WIFI): this is a dummy variable, which takes a value of 1 if there is Wi-Fi available in the cottage and 0 otherwise. In the study of Bilbao-Terol and Valdés [6], the variable included is Internet access.

- Social network (NETWORK): the number of social networking sites in which the cottage is advertised. This variable is also included in the study of Andensson and Hoffmann [29]

- Agro-tourism activities (AGRO): a dummy variable, which takes a value 1 if agro-tourism activities are offered to the visitor. This variable is also included in other studies $[8,28,29]$

- Pets (PETS): a dummy variable taking a value 1 if pets are accepted. This variable is also included in the study of Bilbao-Terol and Valdés [6] and in the study of Vanslembrouck et al. [9].

The land use variables included in the estimation according the literature and $[6,7,9,27-29]$ are as follows:

- Percentage of arable crops of the surface of the total municipality area where the self-catering cottage is located (CROPS).

- Percentage of forest of the surface of the total municipality area where the self-catering cottage is located (The surface of uncultivated land is not included) (FOREST).

- Percentage of grassland of the total surface of the municipality area where self-catering cottage is located (GRASS).

The variable livestock density in the municipality was included in the estimation but was eliminated due to its high correlation with the percentage of surface of arable crops variable.

The localization or geographical variables were also included in other studies in this field $[6,7,9,28,29]$. The localization or geographical variables of the cottages are displayed as follows:

- Distance, measured in metres (m), from each cottage to the nearest beach (DBEACH). The distance to each beach access point from each cottage was determined using a simple distance calculation 
in a GIS environment. The beach access layer was joined spatially to a central point of each cottage, and the distance between the two was calculated. All cottages with direct access to the beach had their distance reset to zero as it was possible to walk directly onto the beach, but all others kept their distance value to the nearest access point.

- Distance, measured in metres (m), from each cottage to the main city (DCITY). The same method used in distance to the beach is applied for distance to the city.

- Central zone (CENTRAL) is a dummy variable that take a value of 1 if the cottage is situated in the central zone of Asturias and 0 otherwise. Asturias is divided into three administrative zones; east, west, and centre. This variable has been included to test whether the situation is different across the zones.

- Coastal zone (COASTAL) is a dummy variable taking a value of 1 if the cottage is located in a coastal municipality.

The variables distance to the motorway closest to the cottage and distance to the railroad were included in the estimation but were later eliminated because of their high correlation with the variable distance near the beach.

Table 3 presents descriptive statistics concerning the relevant variables of the study for the entire sample.

Table 3. Summary statics of the variables for the entire sample $(N=697)$.

\begin{tabular}{ccccc}
\hline Variable & Mean & Std. Dev. & Min & Max \\
\hline PRICE $(€)$ & 119.34 & 58.24 & 15 & 800 \\
MCATEGORY & 0.55 & 0.50 & & \\
HCATEGORY & 0.16 & 0.37 & & \\
PLACES & 5.49 & 2.22 & 2 & 15 \\
WIFI & 0.15 & 0.36 & & \\
NETWORK & 0.36 & 0.94 & 0 & 6 \\
AGRO & 0.01 & 0.11 & & \\
PETS & 0.36 & 0.48 & & \\
CROPS & 1.54 & 1.92 & 0.04 & 15.55 \\
FOREST & 45.53 & 9.05 & 22.12 & 65.27 \\
GRASS & 32.58 & 7.78 & 12.03 & 55.09 \\
DBEACH $(\mathrm{m})$ & $17,485.57$ & $14,090.25$ & 260.82 & $61,513.71$ \\
DCITY $(\mathrm{m})$ & 3983.84 & 2849.56 & 0 & $15,147.27$ \\
CENTRAL & 0.23 & 0.42 & & \\
COASTAL & 0.27 & 0.44 & & \\
\hline
\end{tabular}

The Rosen model does not offer any criterion for selecting the functional form of the hedonic equation so that it has to be determined empirically. Several functional forms have been tested in the empirical works, including the linear, log-log, semi-log (log-linear), inverse semi-log, quadratic forms, the Box-Cox transformation, and non-parametric approaches $[59,60]$. The semi-logarithmic function has been the most predominantly used in applications of the hedonic method for the tourism market $[25,27,28,51,56-58]$.

The Ordinary Least Squares estimation method (OLS) and STATA 9.0 software have been used for estimating Function (1). Heteroscedasticity has been corrected by means of the White procedure. The existence of autocorrelation in the estimation is determined using the Durbin Watson (DW) test. The value of the DW indicates that no autocorrelation exists.

\section{Results and Discussion}

In this study a Box-Cox transformation was considered the dependent variable [61]. The calculation of the maximum-log likelihood Box-Cox shows that $\lambda$ is slightly closer to a 
semi-logarithmic form; therefore this approach is chosen. Also the log-log form was tested with respect to the continuous variables, but better statistical results were obtained with the semi-logarithmic form.

Multicollinearity is explored through the variance inflation factor test (VIF) for each explanatory variable. None of the variance inflation factors calculated exceed the threshold value of four [62] for any of the variables (mean VIF is 1.45), and therefore multicollinearity is not present. Table 4 shows results of the estimation, which we view as satisfactory, as well as variations in prices for rural tourism characteristics.

Table 4. Coefficient estimates for model specifications $(N=697)$.

\begin{tabular}{ccc}
\hline Variable & Coefficient & Std. Error \\
\hline CONSTANT & $3.907^{* * *}$ & 0.144 \\
MCATEGORY & $0.076^{* *}$ & 0.025 \\
HCATEGORY & $0.195^{* * *}$ & 0.037 \\
PLACES & $0.102^{* * *}$ & 0.009 \\
WIFI & $0.072^{*}$ & 0.045 \\
NETWORK & $0.022^{*}$ & 0.012 \\
AGRO & -0.050 & 0.047 \\
PETS & $-0.074^{* *}$ & 0.025 \\
CROPS & $-0.012^{* *}$ & 0.003 \\
FOREST & 0.001 & 0.002 \\
GRASS & $0.004^{* *}$ & 0.002 \\
DBEACH & $-0.000004^{* * *}$ & 0.000001 \\
DCITY & -0.000005 & 0.000004 \\
CENTRAL & $0.072^{* *}$ & 0.033 \\
COASTAL & $0.112^{* *}$ & 0.036 \\
Adjusted R-squared & \multicolumn{2}{c}{0.446} \\
F-statistic & \multicolumn{2}{c}{0.000} \\
Prob (F-statistic) & \multicolumn{2}{c}{. }
\end{tabular}

* Significant at $10 \% .{ }^{* *}$ Significant at $5 \% .{ }^{* *}$ Significant at $1 \%$. Dependent variable: the natural logarithm rent price for high season.

Since the functional form is the semi-logarithmic one, the interpretation of the coefficients is established by Halvorsen and Palmquist [63]. For instance, if a dummy intrinsic variable has a $\beta$ coefficient, the effect on the accommodation's price of the presence of the characteristic is a change of $\left(e^{\beta}-1\right) \times 100$. Therefore, the coefficient of a continuous variable multiplied by 100 is equal to the percentage effect on the accommodation's price for a small change in that variable.

Next, we describe how the different variables included in the model influence the accommodation's price. Beginning with the intrinsic variables, all their coefficients are significant at the conventional levels, except the coefficient for the agro-tourism activities variable that is negative and non-significant. This indicates that the presence of agro-tourism activities on the accommodation's site is not valued by tourists. This result is in line with the studies of Fleischer and Tchetchik [8] and Mollard et al. [28]. They also obtain a negative and non-significant coefficient. Anderson and Hoffman [29] find a non-significant coefficient for this variable but with a positive sign.

The signs of the coefficients of the intrinsic variables are in line with our a priori expectations, except for the acceptance of pets variable, which bears a negative sign. This indicates that allowing pets has a negative effect on the price of accommodation, which decreases by $7.7 \%$, ceteris paribus. It is possible that consumers interpret the presence of pets in the self-service cottages as being a source of dirtiness, unpleasant smells, and insects [56].

The coefficients of the category ranking variables are positive and significant and have a relevant contribution to the price of accommodation, particularly for the highest category. This is a similar finding to most of the other studies $[6,7,28,51,58]$. Therefore, the tenants of cottages pay approximately $8 \%$ more if they choose the medium category instead of the low category; this percentage rises to $21.5 \%$ more if they choose the highest category, all other things being equal. For example, the average price 
of a cottage with the mean characteristics of the sample is $€ 88.6$ for a low-category cottage, $€ 95.58$ for a medium-category cottage, and $€ 107.67$ for the highest category. According to Table 3 , the mean characteristics of the cottage in the sample are (zero when the dummy variable does not reach a mean of 0.5 ): a capacity of five people, not advertised in social network, $1.54 \%$ arable crops, $45.53 \%$ forest, $32.58 \%$ grassland, $17,485 \mathrm{~m}$ to the beach, $3983.84 \mathrm{~m}$ to the capital, medium category, no Wi-Fi, not agro-tourism, no pets, not central, and not coastal.

As expected, another variable that has a relevant contribution to the rental price is the capacity of the cottage. The coefficient of this variable indicates that if the capacity of the cottage increases by $1 \%$, the price increases by $10 \%$, ceteris paribus. For instance, a cottage with the mean characteristics of the sample has an average price of $€ 70.8$ for the lowest capacity, i.e., two people. For the greatest capacity (up to 15 people), this price increases up to $€ 260$. The availability of Wi-Fi increases the accommodation price by $7.5 \%$, ceteris paribus. The average price of a cottage with the mean characteristics of the sample is $€ 95$.6. If the cottage has $\mathrm{Wi}-\mathrm{Fi}$, its price increases to $€ 102.7$. It can be concluded that new technologies are considered particularly important by clients in the case of rural accommodation [49].

The effectiveness of internet advertising in promoting rural tourism increases the price of accommodation by around $2.2 \%$ when a one per cent increase in the number of social networks is produced. This result may be interesting for managers because they can use these networking sites to disseminate important information to attract potential tourists.

The percentage of the various land uses in the municipality areas is the first category of the environmental variables of interest to us here since it allows us to obtain a valorisation of environmental amenities through the rural tourism market. Among the land use variables included in our model, two are significant at the conventional statistical levels of significance and the sign of their coefficients is in accordance with the literature. This indicates that the rural tourism market values the environment surrounding the accommodations.

The negative coefficient of the arable crops variable indicates that the rural tourism market values negatively the presence of this type of agricultural land use. Specifically, a $1 \%$ increase in the surface of arable crops in the municipality where the cottage is sited results in a price decrease of $1.2 \%$, all other things being equal. The variable ranges between $4 \%$ and $15.5 \%$; thus, if the cottage is located in a municipality with a higher percentage of arable crops, its price decreases by $13.8 \%$, ceteris paribus. Vanslembrouck et al. [9] obtain a similar result for the Flemish region. Le Goffe [7] also obtains a negative effect on the price of accommodation price for this type of land use. Andersson and Hoffman [29] find a negative effect but for the livestock production variable. In the Asturias region, the main arable crop is fodder crop production associated with livestock feed. The negative effect of fodder crops on the cottages' prices may be due to the fact that fodder crops involve harmful environmental practices such as the use of fertilizers and pesticides and the destruction of certain species. In addition, the fodder crop is associated with a high density of livestock, which in turn produce air and water pollution derived from their organic waste and the degradation of the soil through stabling [6].

To the contrary, the positive coefficient of the grassland variable indicates that the cottage's price is positively influenced by this type of agriculture land use. Prices increase by $0.4 \%$ when the grassland area in the municipality increases by $1 \%$, ceteris paribus. This result indicates tourists' preference for open spaces and coincides with previous studies $[6,7,9]$. In addition, forestland is valued positively, but the coefficient of the variable is not significant.

The coefficients of the localization variables are significant at conventional statistical levels of significance bearing the expected sign, except for the coefficient of the distance to the main city, which is not significant. We highlight the relevant contribution to the rental price of the variables for a coastal zone and the distance to the nearest beach. If the cottage is located in a coastal municipality, its rental price increases by around $12 \%$, ceteris paribus. In turn, a cottage situated close to a beach is $24.5 \%$ more expensive than the most remotely situated one. These results indicate the attractiveness of a coastal landscape to the rural tourism market. The main objective of this study is not to analyse this particular type of environmental amenity, but nevertheless these results are interesting for future work. 
Taylor and Smith [25], Hamilton [27], and Rigall-Torrent and Fluvià [51] all found that the proximity of the coast exerts a strong influence on the price of accommodation. On the other hand, the coefficient of the central zone variable indicates that if the cottage is located in the central region, its price increases by $7.5 \%$. This may be because the central area of the region offers more services and has better means of communication.

\section{Conclusions}

In this paper, the hedonic price method has been applied in order to explore the influence of agricultural land use on the price of self-catering cottage accommodation. In general, the self-catering cottages are ancient farms or rural dwellings with traditional architecture, which are restored for tourism use. By promoting these traditional rural buildings, rural tourism reflects sustainability principles, producing a link between cultural heritage, agricultural landscape quality, and a sense of local identity.

A contribution of this study has been to utilize the estimated variables derived from GIS to measure the self-catering cottages' locations and their proximity to amenities, including environmental amenities. The use of GIS measures improves the hedonic price model specification since it provides more accurate value estimates of the location and the proximity to amenities.

We find considerable empirical support to suggest that agricultural land uses have an important impact on the price of self-catering cottages. Specifically, a high percentage of grassland in the municipality where the cottage is located has a positive effect on rental prices, while a high percentage of arable crops has the opposite effect. Although the hedonic prices estimated signify a weak relationship with environmental amenities such as diversity, quality water and air, and wildlife, they can be used for decision-making on environmental policies, land use conflict resolution, and rural tourism sustainability. For example, the public sector can calculate payments to the farmers for abandoning harmful land use practices or alternatively collect an ecological tax from tourists. Additionally, the hedonic prices may be used in the application of cost-benefit analysis to assess environmental improvements. Having said this, our study suffers from limitations because it only takes into account the benefits obtained for the owners of rural tourism accommodation and not by other agents such as the owners of rural houses and the public in general.

Another finding of our research is the relevant contribution of other landscape features, in particular coastal and beach landscapes, on the rental of self-catering cottages as accommodation. A future line of research could be to analyse the externalities produced by these types of landscapes.

An alternative line of research could be to include non-traditional rural tourism accommodation in the study (such as hotels, camping, and apartments) and to compare these with the results from the analysis of self-catering cottages to ascertain the impact of each on rural tourism sustainability related to heritage and rural preservation.

This paper considers features related to accommodation, and the analysis could be improved by also considering the characteristics or preferences of the tourists.

Acknowledgments: We gratefully acknowledge the financial support provided by the Spanish Ministry of Education, Projects ECO2015-66521-P and ECO2015-66184-R. We thank the anonymous referees and editor for their useful suggestions to improve the final paper.

Author Contributions: The conceptualisation of the paper is attributed to C.B.-T., L.V., and E.D.V., who prepared the database compiling the information on accommodation from the Asturias' Tourism Accommodation Guide. They also write the part of the manuscript relating to the characteristics of the study area and the literature review. C.B.-T and V.C.-F. write the rest of the article and carried out the estimation. C.B.-T. interpreted the results of the estimation. V.C.-F. compiled the information from the different sources and merged them through a Geographical Information System. Therefore, she also estimated the location variables. All the authors contributed to the revision of the paper and checked the references.

Conflicts of Interest: The authors declare no conflicts of interest. The data obtained from the Government of Asturias are under an open access publication (under the terms and conditions of the Creative Commons Attribution (CC BY) license-CC-BY 3.0. 


\section{References}

1. Takai, H.; Persensen, S.; Johnsen, J.O.; Metz, J.H.M.; Groot Koerkamp, P.W.G.; Uenk, G.H.; Phillips, V.R. Concentrations and Emision of Airborne Dust in Livestock Buildings. J. Agric. Eng. Res. 1998, 70, 59-77. [CrossRef]

2. Geiger, F.; Bengtsson, J.; Berendse, F.; Weisser, W.W.; Emmerson, M.; Morales, M.B.; Ceryngier, P.; Liira, J.; Tscharntke, T.; Winqvist, C.; et al. Persistent negative effects of pesticides on biodiversity and biological control potential on European farmland. Basic Appl. Ecol. 2010, 11, 97-105. [CrossRef]

3. Rosen, S. Hedonic Prices and Implicit Markets: Product Differentiation in Pure Competition. J. Political Econ. 1974, 82, 35-55. [CrossRef]

4. Garrod, G.D. Using the Hedonic Pricing Model to Value Landscape Features. Landsc. Res. 1994, 19, $26-28$. [CrossRef]

5. Choumert, L.; Travers, M.; Delatre, C.; Beaujouan, V. Capitalization of green spaces into housing values in the city of Angers: A hedonic approach. Presented at the First Conference on Landscape Economics, Vienna, Austria, 5-8 July 2009.

6. Bilbao-Terol, C.; Valdés, L. The environmental setting, farming activities and rural accommodation prices. Investig. Reg. J. Reg. Res. 2015, 33, 29-47.

7. Le Goffe, P. Hedonic pricing of agriculture and forestry externalities. Environ. Resour. Econ. 2000, 15, 397-401. [CrossRef]

8. Fleischer, A.; Tchetchick, A. Does rural tourism benefit from agriculture? Tour. Manag. 2005, $26,493-501$. [CrossRef]

9. Vanslembrouck, I.; Van Huylenbroek, G.; Van Mennesel, J. Impact of agriculture on rural tourism: A hedonic pricing approach. J. Agric. Econ. 2005, 56, 17-30. [CrossRef]

10. Shimizu, C. Estimation of hedonic single-family house price function considering neighborhood effect variables. Sustainability 2014, 6, 2946-2960. [CrossRef]

11. European Communities. The Future of Rural Society. COM (88) 501 of 29.07.1988. Bruselas. Available online: https:/ / ec.europa.eu/agriculture/sites/agriculture/files/cap-history/crisis-years-1980s / com88-501_en.pdf (accessed on 29 August 2017).

12. Commission of the European Communities. Community Action to Promote Rural Tourism. Communication from the Commission COM(90) 438 Final Brussels. 1990. Available online: http:/ / aei.pitt.edu/3700/1/3700. pdf (accessed on 29 August 2017).

13. Council Regulation (EC) No 1698/2005 of 20 September 2005 on Support for Rural Development by the European Agricultural Fund for Rural Development (EAFRD). 2005. Available online: http:/ / eur-lex.europa. eu/legal-content/EN/TXT/?uri=LEGISSUM:160032 (accessed on 29 August 2017).

14. Prideaux, B. Creating Rural Heritage Visitor Attractions-The Queensland Heritage Trails Project. Int. J. Tour. Res. 2002, 4, 313-323. [CrossRef]

15. Porto, S.M.C.; Leanza, P.M.; Cascone, G. Developing Interpretaion Plans to Promote Traitional Rural Buildings as Built Heritage Attractions. Int. J. Tour. Res. 2012, 14, 421-436. [CrossRef]

16. De Montis, A.; Ledda, A.; Ganciu, A.; Serra, V.; De Montis, S. Recovery of rural centres and 'albergo diffuso': A case study in Sardinia, Italy. Land Use Policy 2015, 47, 12-28. [CrossRef]

17. Leanza, PM.; Porto, S.M.C.; Sapienza, V.; Cascone, S.M. A Heritage Interpretation-Based Itinerary to Enhance Tourist Use of Traditional Rural Buildings. Sustainability 2016, 8, 47. [CrossRef]

18. Garcia, A.L.; Ayuga, F. Re-use of abandoned and the rural landscape: The situation in Spain. Trans. ASABE 2007, 50, 1383-1394. [CrossRef]

19. Porto, S.M.C.; Gascone, G. A building characterization-based method for the advancement of knowledge on external architecture features of traditional rural buildings. Inf. Contr. 2013, 65, 481-496. [CrossRef]

20. Randelli, F.; Romei, P.; Tortora, M. An evolutionary approach to the study of rural tourism-The case of Tuscany. Land Use Policy 2014, 38, 276-281. [CrossRef]

21. LaPan, C.; Barbieri, C. The role of agritourism in heritage preservation. Curr. Issues Tour. 2014, 17, 666-673. [CrossRef]

22. Cànoves, G.; Villarino, M.; Priestley, G.; Blanco, A. Rural Tourism in Spain: An analysis of recent evolution. Geoforum 2004, 35, 755-769. [CrossRef] 
23. Busby, G.; Rendle, S. The transition from tourism on farms to farm tourism. Tour. Manag. 2000, 21, 635-642. [CrossRef]

24. Walford, N. Patterns of development in tourist accommodation enterprises on farms in England and Wales. Appl. Geogr. 2001, 21, 331-345. [CrossRef]

25. Taylor, L.O.; Smith, V.K. Environmental Amenities as a Source of Market Power. Land Econ. 2000, 76, 550-568. [CrossRef]

26. Hunt, L.M.; Boxall, P.; Englin, J.; Haider, W. Remote tourism and forest management: A spatial hedonic analysis. Ecol. Econ. 2005, 53, 101-113. [CrossRef]

27. Hamilton, J. Coastal Landscape and the Hedonic Price of Accommodation. Ecol. Econ. 2007, 62, $594-602$. [CrossRef]

28. Mollard, A.; Rambonilaza, T.; Vollet, D. Environmental Amenities and Territorial Anchorage in the Recreational-Housing Rental Market: A Hedonic Approach with French Data. Land Use Policy 2007, 24, 484-493. [CrossRef]

29. Andersson, H.; Hoffmann, R. Spatial Competition and Farm Tourism. A Hedonic Pricing Model. In Proceedings of the Annual Meeting, Orlando, FL, USA, 27-29 July 2008.

30. Suárez Vega, R.; Santana Jiménez, Y.; Hernández Guerra, J.M. Valoración económica de las características espaciales de las casas rurales en Gran Canaria. Rect@ Actas 2009,17,1-17.

31. Nelson, J.P. Valuing rural recreation amenities: Hedonic prices for vacation rental houses at deep creek lake, Maryland. Agric. Resour. Econ. Rev. 2000, 39, 485-504. [CrossRef]

32. Tourism Asturias. Available online: https://www.turismoasturias.es/en/acerca-de-asturias (accessed on 17 July 2017).

33. Asturian Society of Economic and Industrial Studies (Sociedad Asturiana de Estudios Económicos e Industriales-SADEI). Available online: www.sadei.es (accessed on 17 July 2017).

34. Geoportal of the Territorial Information System of the Principality of Asturias (SITPA) (Geographic Information Systems). Available online: http://sitpa.cartografia.asturias.es/Geoportal/extlayout.aspx? userId=FZr4XHq0PJA=\&lang=es (accessed on 17 July 2017).

35. Geographic Information System from the Nature Data Bank (Banco de Datos de la Naturaleza-BDN). Ministry of Agriculture, Fisheries Food and Environment of the Government of Spain. Available online: http:/ / sig.mapama.es/bdn/visor.html (accessed on 28 August 2017).

36. Instituto Nacional de Estadistica (INE). Spanish Regional Accounts, First Estimation for 2016. Available online: http:/ / www.ine.es/dyngs/INEbase/en/categoria.htm?c=Estadistica_P\&cid=1254735576581 (accessed on 17 July 2017).

37. Valdés, L. (Ed.) El Turismo en Asturias en 2016. Oviedo: Tourist Information System of Asturias and Gobierno del Principado de Asturias. 2017. Available online: https://drive.google.com/file/d/ 0Bw8WddWZnp77NXlfT3c4N2Ftb00/view (accessed on 21 July 2017).

38. Instituto Nacional de Estadistica (INE). Hotel Industry and Tourism Statistical Operations. Available online: http:/ / www.ine.es / dyngs / INEbase/en / categoria.htm?c=Estadistica_P\&cid=1254735576863 (accessed on 21 July 2017).

39. Yagüe, R.M. Rural tourism in Spain. Ann. Tour. Res. 2002, 29, 1101-1110. [CrossRef]

40. Valdés, L. El turismo rural: Una alternativa diversificadora. Líneas estratégicas de su Expansión. Papeles Econ. Esp. 2004, 102, 298-315.

41. Pulido, J.I. (Ed.) El Turismo Rural. Estructura Económica y Configuración Territorial en España; Síntesis: Madrid, Spain, 2008.

42. Pulido, J.I.; Cárdenas, P.J. El turismo rural en España. Orientaciones estratégicas para una tipología aún en desarrollo. Bol. Asoc. Geógr. Esp. 2011, 56, 155-176.

43. Valdés, L.; del Valle, E. Situación y perspectivas del turismo rural en España. Estrategias de actuación. Papeles Econ. Esp. 2011, 128, 201-220.

44. Jenkins, T. Putting postmodernity into practice: Endogenous development and the role of traditional cultures in the rural development of marginal regions. Ecol. Econ. 2000, 34, 301-314. [CrossRef]

45. Nilsson Per, A. Staying on farm. An ideological background. Ann. Tour. Res. 2002, 29, 7-24. [CrossRef]

46. Dall'Ara, G. Manuale dell'Albergo Diffuso. L'idea, la Gestión, il Marketing dell'Ospitalità Diffusa; Franco Angel: Milano, Italy, 2010. (In Italian) 
47. Valdés, L. (Ed.) El Turismo Rural en Asturias en 2014. Oviedo: Tourist Information System of Asturias and Gobierno del Principado de Asturias. 2015. Available online: https://drive.google.com/file/d/ 0Bw8WddWZnp77QjFNMjNQME1Pa28/view (accessed on 27 August 2017).

48. Molera, L.; Albaladejo, I.P. Profiling segments of tourists in rural areas of South-Eastern Spain. Tour. Manag. 2007, 28, 757-767. [CrossRef]

49. Hernández-Maestro, R.; González-Benito, O. Rural Lodging Establishments as Drivers of Rural Development. J. Travel Res. 2013, 53, 83-95. [CrossRef]

50. Del Valle Tuero, E. El Turismo Rural en España: Análisis de la Evolución del Modelo de Desarrollo y Perspectivas Futuras. Ph.D. Thesis, Universidad de Vigo, Vigo, Spain, 2014. Available online: http://hdl. handle.net/11093/632 (accessed on 27 August 2017).

51. Rigall-I-Torrent, R.; Fluvià, M. Managing Tourism Products and Destinations Embedding Public Good Components: A Hedonic Approach. Tour. Manag. 2011, 32, 244-255. [CrossRef]

52. Baranzini, A.; Ramirez, J.; Schaerer, C.; Thalmann, P. (Eds.) Hedonic Methods in Housing Markets; Springer: New York, NY, USA, 2008.

53. Bilbao-Terol, C.; Cañal-Fernandez, V. The Market Valuation of Ethical Assets in Spain: An Application of the Hedonic Pricing Method. Bus. Ethics 2014, 23, 343-363. [CrossRef]

54. Freeman, A.M., III. The Measurement of Environmental and Resource Values, Theory and Methods; Resources for the Future: Washington, DC, USA, 2003.

55. CartoCiudad: Cartociudad Project. 2009. Available online: www.cartociudad.es/portal (accessed on 17 August 2017).

56. Bilbao, C.; Valdes, L. Evaluation of the profitability of quality labels in rural tourism accommodation: A hedonic approach using propensity score matching. Appl. Econ. 2016, 48, 3254-3263. [CrossRef]

57. Sinclair, M.T.; Clewer, A.; Pack, A. Hedonic Prices and the Marketing of Package Holidays: The Case of Tourism Resort in Málaga. In Marketing Tourism Places; Ashworth, G., Goodall, B., Eds.; Routledge: London, UK, 1990; pp. 85-103.

58. Clewer, A.; Pack, A.; Sinclair, M.T. Price Competitiveness and Inclusive Tour Holidays in European Cities. In Choice and Demand in Tourism; Johnson, P., Thomas, B., Eds.; Mansell: London, UK, 1992; pp. 123-143.

59. Ekeland, I.; Heckman, J.; Nesheim, L. Identifying Hedonic Models. Am. Econ. Rev. 2002, 92, $304-309$. [CrossRef]

60. Landajo, M.; Bilbao-Terol, C.; Bilbao-Terol, A. Nonparametric Neural Network Modeling of Hedonic Prices in the Housing Market. Empir. Econ. 2012, 42, 987-1009. [CrossRef]

61. Box, G.E.P.; Cox, D.R. An analysis of transformation. J. R. Stat. Soc. 1964, 26, 211-252.

62. Fox, J. Regression Diagnostics: An Introduction; Sage: Newbury Park, CA, USA, 1991.

63. Halvorsen, R.; Palmquist, R. The Interpretation of Dummy Variables in Semilogarithmic Equations. Am. Econ. Rev. 1980, 70, 474-475. [CrossRef]

(C) 2017 by the authors. Licensee MDPI, Basel, Switzerland. This article is an open access article distributed under the terms and conditions of the Creative Commons Attribution (CC BY) license (http://creativecommons.org/licenses/by/4.0/). 